\title{
Using IT to Inform and Rehabilitate Aphasic Patients
}

\author{
Cecília Sik Lányi, Zoltán Geiszt, and Viktor Magyar \\ University of Veszprém, Hungary
}

lanyi@almos.vein.hu geiszt@vision.vein.hu magyarviktor@gmail.com

\begin{abstract}
Our age, building around the World Wide Web, is called the era of information. This usually means simple access to news, theoretical or practical knowledge in science and engineering. But, less in the forefront, new ways of representation, embodiment of information give a very powerful hand in treatment of special patients. Recognising these offerings of modern information technology, a group of language therapist asked us to collaborate in developing a new therapy for aphasic patients. Aphasia is an impairment of language, affecting the production or comprehension of speech and the ability to read or write. The most common version of aphasia is acquired aphasia: about $23-40 \%$ of stroke survivors suffer from this impairment. The rehabilitation of aphasia is a medical, special treatment (speech therapy), which is the task of psychologists or language therapists. We developed a multimedia rehabilitation software package and an interactive virtual world, a Virtual Home to improve readiness of speech and ability of orientation for helping the therapy. Both programs aim at strengthening the patients' grasp of every-day vocabulary and improving their spelling skills with demonstrative environments and graded tasks. In this paper we present the development processes and the real-life use of this new treatment, accompanied by the testing results.
\end{abstract}

Keywords: Software development process, multimedia, virtual environment, Virtual Home, aphasia, stroke, rehabilitation, IT.

\section{Introduction}

The new ways of representation of information offered new possibilities in medical treatment, especially where the impairment has its root in mental blockades. Recognising these offerings, a group of language therapists from Kozmutza Flora Special Primary School and Talent Developing College asked us to collaborate in developing a new therapy for aphasic patients. As the name suggests, children with learning difficulties, especially those with aphasia, are educated in this institution. Within the boundaries of the project a multimedia rehabilitation software and a virtual world were created. The former is named "Word-instructor" and it aims to teach the aphasic pa-

Material published as part of this publication, either on-line or in print, is copyrighted by the Informing Science Institute. Permission to make digital or paper copy of part or all of these works for personal or classroom use is granted without fee provided that the copies are not made or distributed for profit or commercial advantage AND that copies 1) bear this notice in full and 2) give the full citation on the first page. It is permissible to abstract these works so long as credit is given. To copy in all other cases or to republish or to post on a server or to redistribute to lists requires specific permission and payment of a fee. Contact Publisher@InformingScience.org to request redistribution permission. tients the most important everyday words (Sik Lányi, Bacsa, Mátrai, Kosztyán, \& Pataky, 2004). The latter one is called "Virtual Home", and helps the patients to develop readiness of speech and improve their ability of orientation for promoting the therapy (Sik Lányi \& Hajnal, 2005). The shared goal of this software is to teach a vocabulary of the most important everyday words. 


\section{What is Aphasia?}

Stroke is a term used to describe a sudden neurological deficit within the brain. The extent and precise location of damage is unique to the individual, thus which function stays intact and what the observed behaviour will be, is also individual to each stroke survivor. A thorough assessment of the patient's cognitive and motor function is the first stage of rehabilitation. For most patients the priority is to facilitate a return home as soon as it is safe and timely for them to do so (Pridmore, Hilton, Green, Eastgate, \& Cobb 2004).

Aphasia is an impairment of language, an acquired communication disorder that impairs a person's ability to process language, but does not affect intelligence. It also impairs the ability to speak and understand others and most people with aphasia experience difficulty in reading and writing.

The severity of aphasia can reach such a high level that any means of communication with the patient is almost impossible, while on the other hand it can be as mild that exerts only an almost negligible effect on the patient's life. The level of severity can wildly change between the language skills of one single patient. It is also common that only one aspect of language use is affected by aphasia, for example the patient has problems only constructing a sentence from words, while has no difficulty in selecting the proper words. But usually more than one aspects of communication are impaired, while some language channels remain accessible only for a limited exchange of information. Therapists' main concern is the gauging of the level of functionality of these channels, and the estimation of possible achievements of a treatment on the channels remained available (Maureen, 2005).

\section{What Causes Aphasia?}

Most common cause of aphasia is stroke - about $23-40 \%$ of stroke survivors acquire aphasia. It can also result from head injury, haemal affection of the brain, brain-tumour, meningitis or other neurological injuries. It is estimated that in the United States about one million people have acquired aphasia, or 1 in every 250 people. It is more common than Parkinson's Disease, cerebral palsy or muscular dystrophy. About $1 / 3^{\text {rd }}$ of severely head-injured persons have aphasia. However, most people have never heard of it (http://www.aphasia.org/). The majority are the result of stroke. About one third of severely head-injured persons have aphasia (Maureen, 2005). In Hungary almost 35000 new stroke patients are registered every year. 50\% of them have mental disorder and 30\% aphasia (Óvári \& Nagy, 1999).

The patients' understanding of their environment is usually undisturbed, and their receptive language skills are also less affected. Although in the case of the latter one the amount of exceptions

is too numerous to handle them as negligible factors, the main problem arises when their speaking skills are put into focus. These patients can speak only in a slow, disconnected manner or even cannot speak at all. In addition writing and reading are also problematic for them.

But before taking an in-depth look on the varieties of aphasia, a compact classification of other speech defects should be made on the basis of cause.

1. Speech defects based on the injury of vocal and hearing organs along with cerebrospinal mechanisms that are controlling them directly.

2. Psychological and social speech defects.

3. Speech defects accompanying insanity or mental problems.

4. Speech defects emerging with the diffuse, largely extensive, progressive ruining of the cerebral cortex. 
5. Childhood speech defects. (They are present in childhood only in extreme cases and differ wildly from the adulthood counterparts).

Varieties and special features of aphasia (Maureen, 2005)

As it was stated before, aphasia can take many forms, and after years of examination of aphasia the categorisation process is still in progress.

- Global aphasia is the severest version of all the varieties, and it stands for cases with patients who are unable to produce more than a few recognizable words and understand only little spoken language, while not able to read or write at all.

- Broca's aphasia also reduces the spoken language of the patients to very short utterances with clumsy pronunciation. Their vocabulary is limited, but the remaining three basic language skills: listening, reading and writing are relatively good.

- Wernicke's aphasia has the balance in its other extreme: the listening skills are the ones mostly impaired, while speech is usually free of any severe affection. Although this variety being frequently called fluent aphasia, the mentioned spoken skill is far from normal, and the reading and writing ability of the patients belonging to this group are severely damaged.

- Mixed non-fluent aphasia covers the group of patients with spoken skills resembling that of more severe Broca's aphasia, while their writing and reading skills are restricted to elementary level.

- Anomic aphasia is applied to patients with grammatically correct but contextually confused speech utterances. In this case to main problem is the persistent inability to find the words for the things they want to name both in speech and writing. The other two basic language skills, listening and reading is adequate.

- Other varieties of aphasia: As it was indicated before, there are a number of other possible combinations of deficits that do not exactly fit into the former categories, their proper classification (or the need for it) are still subjects to many debates.

\section{Recovery from Aphasia}

If symptoms last longer than two or three months after a stroke, complete recovery is unlikely. However, it is important to note that some people continue to improve over a period of years and even decades. Improvement is a slow process that usually involves both helping the individual and the family to understand the nature of aphasia and learning compensatory strategies for communication.

\section{Rehabilitation Methods}

Aphasia is often referred to as the foster child of logopaedia, reflecting the fact that nearly all the contemporary rehabilitation methods approach the problem from a linguistic point of view. They hardly take account of the cognitive aspects of the speech deficiency.

These usual treatments intend to improve the remained communication capacity with the help of a therapist. Generally speaking, they implement one-way communication, in which the therapist asks and the patient only gives answers. This limited role obviously does not allow the patients to test their speaking and listening skills in a number of situations.

The main schools of aphasia-therapy are listed below. 
- Didactic: A treatment of pedagogical basis. It aims to restart language use with tools of primary school first language teaching.

- Behaviourist: This way intends to change verbal behaviour with the tools of the stimulusresponse automatisms view, thus applies a programmed way of teaching.

- Rearrangement of functions: A theory developed by Alexandr R. Lurija after the Second World War in the Soviet Union. He depicted the recovery of functions in three steps:

○ Deinhibition: The release of functions under temporary block.

- Substitution: The rearrangement of functions from the damaged part of a brain hemisphere to its non-damaged section.

- Reorganisation: The reorganisation of the whole functional system.

- Pragmatic: The former strict code-oriented view is abandoned by the pragmatists due to the recognition of the fact that the aphasic patients are more effective in communication in real life situations than it is predicted from the measured level of their language skills. Instead of concentrating on the correctness of language structure, the pragmatic school puts the emphasis on helping the patients to use their available verbal and non-verbal language tools to solve real-life situations.

- Neo-Classic: This method, based on the classic behaviourist view and programmed teaching, targets the conditioning of the neural functions through stimulus-response connections.

- Neuro-linguistic: For gaining a better understanding and more compact view on the nature of aphasia, a general approach raised in the 1960-s that called for the immersion of the concerned fields of science, namely neurobiology and linguistics. Through the interdisciplinary science of neurolinguistics a new view appeared in aphasia research.

IT is the exploration of a new way in aphasia therapy, not only among the other traditional methods but also in cooperation with some. It grants not only the possibility of the simulation of the mentioned therapist-patient interaction, but also various other tasks and knowledge can be presented using modern day IT.

\section{Multimedia, Virtual Reality and Virtual Environment in Rehabilitation}

Multimedia and Virtual Reality (VR) are becoming increasingly important in preventive and assistive healthcare and rehabilitation. There are an ever increasing number of $3 \mathrm{D}$ applications and animations in the forthcoming multimedia software. The review of current VR applications shows that VR can be considered a useful tool for diagnosis, education and training of healthcare staff and also an education, training and rehabilitation tool for patients.

\section{What is Multimedia?}

The term 'multimedia' has the literal meaning of 'more than one medium', but is used in three different and complementary senses: first to describe the channels through which information is delivered, including printing on paper, television, radio, telephone, CD-ROM and the Internet; second to describe the content, as a mixture of still and moving images, text, graphics and sound; and third to describe the style of interaction through which the user may explore the content, taking advantage of the hierarchies and associations within the material via links connecting a variety of database resources. In this sense multimedia is the meeting ground of technology, design and human factors (MacDonald, 1996). 


\section{Definition of Virtual Environment and Virtual Reference}

Virtual Environment (VE) is defined as a synthetic, spatial (usually 3D) world seen from a firstperson's point of view. The view in a VE is under real-time user-control.

Virtual Reality (VR) is synonymous with VE. We use the term VE in this article because the term VR is associated with unrealistic hype generated by the media (Bowman, Kruijff, LaViola, \& Poupyrev, 2004).

Multi-sensory VEs are closed-loop systems comprising humans, computers, and the interfaces through which continuous streams of information flow. More specifically, VEs are distinguished from other simulator systems by their capacity to portray three-dimensional (3D) spatial information in a variety of modalities, their ability to exploit users' natural input behaviours for humancomputer interaction, and their potential to "immerse" the user in the virtual world (Stanney, 2002).

Virtual Reality is a discipline of computer science that allows computer based models of the real world to be generated, and provides humans with a means to interact with these models through new human-computer interfaces. It can either be immersive, where the user feels physically present in the VE typically using a head-mounted display, or non immersive, where a handheld interface allows interaction with objects on a computer screen.

\section{VE as a Rehabilitation Tool}

Virtual Environment and VR can be viewed as an advanced computer interface that allows the user to interact and become immersed within computer-generated simulated environments. Rapid development in modern technology and sophisticated computer systems have made it possible to display complex visual images that change in response to instructions from users on desktop computers. According to Lam, Tam, Man and Weis (2004), VEs demonstrate many of the characteristics of an ideal training medium. Virtual Environments are especially valuable when training in real life situations will be impractical, dangerous, logistically difficult, unduly expensive, or too difficult to control. The person can actively interact with simulated worlds by using interface devices. Its realism and versatility makes VR a suitable and innovative approach in rehabilitation. A number of researches have supported the use of VR in rehabilitation, both for assessments and treatments among physical, cognitive and psychological conditions (Lam et al., 2004).

The development work so far (Edmans, 2004) has focused extensively and necessarily on means to interface with the VE. In the upcoming phase we have to concentrate more upon the VE itself and the question of the actual use of systems as a rehabilitation tool in clinical practice. This requires attention to the reasons why these types of technologies have potential value in rehabilitation, and why they may fail. The potential rehabilitation benefits of practice in a VE include: (Edmans et al., 2004)

- Treatment of the cognitive process of task performance can take place sooner in a VE than in a real environment.

- VE can avoid training in potentially hazardous settings.

- Working with VE can be enjoyable and compulsive, thus providing motivational benefits.

- VE can allow the learning process to be more strictly controlled and defined than might be possible in the real environment.

The potential rehabilitation drawbacks of VEs are:

- Interfacing with the VE could be too difficult for patients. Patients cannot benefit from rehabilitation if they do not participate in it. 
- The system could be too difficult, unrealistic or non-intuitive to be enjoyable and motivational. Patients may not benefit if not motivated.

- The system could fail to train the cognitive skills that are lost.

- Training in the virtual environment could fail if the patient cannot generalise the skills to real world settings.

\section{IT for Aphasic Patients}

Aiding different aphasia therapies, various speaking skill improving, interactive multi-media programs have been developed. Their usual concept is the automation of the traditional face-to-face method (Bognár, Várady, \& Fördős, 2003). This term, as mentioned before, refers to the fact that the patient solves different tasks in close cooperation with the therapist during normal therapy. But these interactions are not limited to the therapist-patient type, another version of the therapy concentrates on patients' team work. Self-help groups can promote observable development in the state of special needs persons, while also making it possible to reduce the amount spent on therapists. Obviously their assembly is problematic even with the use of the internet, since interaction via ordinary chat tools may be highly difficult for them. The main problem is derived from their word finding and spelling difficulties. Due to this, the normally dynamic chat-conversation likely becomes halting, which might cause frustration and outweigh the beneficial effects of the group work. Spaniol, Springer Klamma and Jarke (2004) designed and implemented a new chat tool for such groups to overcome these problems.

The idea was simple: they made possible for everyone with an intention to help to join in any conversation (if help was asked), and to give hints on the next word or expression that caused the delay. In this way, the inner connections of the group are strengthened and the participants get really involved and become responsible members of the group. A large number of therapists are also members of these groups, but care is taken when accounts are given out to avoid anyone from joining who does not have the patients' best interests at heart.

Through entering the chat itself, therapists can monitor the development of their patients, and can modify the therapy according to the results. In addition, the system is able to provide a transcript of the conversations into a handful of selectable output media for later assessment.

Obviously this project focused on the communication itself, and the created system is not a thematic learning tool. In addition it is highly dependant on the abilities of its participants; therefore it becomes really effective only in a later stage of the treatment.

Virtual reality is the latest tool recognised by the professionals of this field: it does not open up new possibilities only, but it shows a completely new way of medical treatments. Judging from our experiences, contemporary VR applications mainly target the rehabilitation of stroke (instead of aphasia), for which cause a high number of virtual environments have been developed all over the world (Sik Lányi, 2006). One of the most interesting of these researches is the ViviedGroup's Gesture Xtreme projected VR scenarios (control of the type, speed, location and direction of all stimuli) and documentation of all subjects' performance (Kizony, Katz, Weingarden, \& Weiss, 2002; Kizony, Katz, \& Weiss, 2004). It is a unique approach to VR, which might have important applications for rehabilitation of children and adults with physical and/or cognitive impairment (www.vividgroup.com). Another way of developing VR applications is to start from existing occupational treatment methods and develop platforms for home rehabilitation. Such telemedically controlled systems using low-cost web-based video/audio telemedicine units have much potentials (Broeren, Georgsson, Rydmark, \& Stibrant Sunnerhagen, 2002). Connor, Wing, Humphreys, Bracewell, and Harvey (2002) in San Francisco used a haptic guided errorless learning unit with 
an active force feedback joystick and computer for rehabilitation of cognitive deficits following stroke.

To test spatial memory a virtual reality Arena task was designed, consisting of a circular space surrounded by pattern rendered walls. The participants had to navigate within the arena using a joystick to signal motion. Brain activity was recorded during the different phases of the task in control participants and then in hippocampaly damaged patients (Morris, Parslow, Fleminger, Brooks, Giametro, \& Rose, 2002).

The project called "Virtual Reality for Brain Injury Rehabilitation" developed at Lund University in Sweden produced many interesting results. They investigated usability issues of VR technology for people with brain injury, examined the issue of transfer and training, developed different applications of VR for training of daily tasks: kitchen work, an automatic teller machine and finding ones way in a complex environment, virtual vending and automatic service machines (Davies, 2002), (Wallergård et al., 2002). VR has been used to test executive functioning in patients with focal frontal lesions. It was done in a multi-componential VR procedure, the Bungalow Task, it was developed to test strategy formation, rule breaking and prospective memory (Morris, Kotitsa, Bramham, Brooks, \& Rose, 2002).

The V.E.Ne.Re. (Virtual Executive Neuropsychologocal Rehabilitation) consists in the construction and validation of artificial environments based on VR technologies, aimed for cognitive rehabilitation of executive functions (frontal lobe dysfunction; dysexecutive syndrome) (Lo Priore, Castelnuovo, \& Liccione, 2002).

A new VE was studied to examine the possibility to influence empathy on caregiver personal. The VE looked like a normal apartment and could be experienced with or without different perceptual disorders of stroke. Results from observations and interviews indicate that the simulator, in spite of problems of usability, was effective in influencing caregivers empathy (Maxhall et al., 2004).

Our work at the University of Veszprém is more focused on the earlier stages of recovery, on the return to the world.

\section{Developing the Multimedia Software and Virtual Environment}

At the University of Veszprém our group started the development of educational multimedia programs for special needs users approximately ten years ago. Since then a great deal of such software has been created. Recently the interest of our group has been more directed towards developing virtual reality programs, especially with the needs of disabled people in mind. Most of our multimedia software was developed by Macromedia Director or Flash and the virtual worlds created by VRML or Maya.

\section{Development Environment of the Multimedia Rehabilitation Soft- ware "Word-instructor"}

The "Word-instructor" software was developed in Flash MX (http://www.macromedia.com). The virtual environment 'Virtual Home' was developed in MAYA. The interactive engine was written in $\mathrm{C}++$ with the help of Irrlich 3D Game Engine.

The basis of the "Word-instructor" multimedia software (Bacsa, 2004) is the books "Everyday Life Activities" by Jacqueline Stark (Stark, 1998, 2003, 2005) and "Speak without fear" by Marianna Takácsné-Csór (1986). The second book has more exercises, and they are arranged in a graded pattern of reaching ever more difficult ones as a person goes through the book. After clas- 
sifying the tasks and making several groups from them, we designed the main menu. We took the following items into account: simplicity, easy surveying, handy using, and avoiding attentiondistraction.

An eHealth system (Medve, Szakolczai, \& Kozmann, 2004) connects the patient and the professionals/doctors. Both of them have their own points of views about the usually idealised system they wish to use. As we know such a system does not exist, though system designers have to make efforts to produce devices (hardware) and programs (software) suitable to as much viewpoints as possible.

The programming was started after the searching for simple figures and illustrations which are easy to see. At the beginning we had to consider that there were a lot of similar exercises. The program had to be terminable. The number of the visible pictures on the screen is not the same in every task therefore we had to watch out for their sizes. The order of the cast members on the stage was also important. The pictures are randomly arranged in every skill level of the program. In this way protection against monotony is assured. By using the interactivity of our software the computer informs the user about the right or wrong solution. Both cases are marked with adequate figure and sound.

\section{Introduction of the Multimedia Software}

The program starts with a task being chosen. The user may not be able to use the software alone in this phase of the rehabilitation, so the guidance of a teacher or therapist is required. Answering the questions does not happen in a fixed order, so it is possible to begin the practice from his (or her) own skill level.

We took care to ensure interactive participation of the patient by ensuring each task required some manipulation. The number of the right answers isn't displayed with points but only with illustrating animations. The program is user friendly, it does not require special knowledge and everybody is able to understand how to use it in a few seconds (Sik Lányi, Bacsa, Mátrai, \& Kosztyán, 2004; Sik Lányi, Bacsa, Mátrai, Kosztyán, \& Pataky, 2004).

\section{The Structure of the Menu}

There are three pictures in the main menu of the program (Fig. 1). Here the patient or the teacher can choose from the languages with a mouse click. The next step after choosing the language is to give the user's first and family name (Fig. 2). The user's name is required for later development of the records.

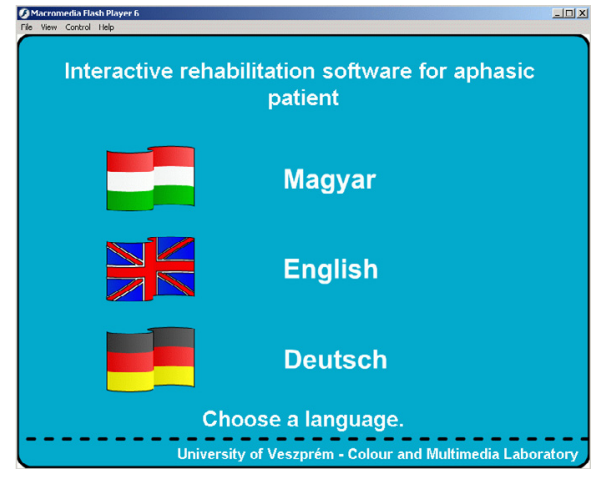

Figure 1: Main menu

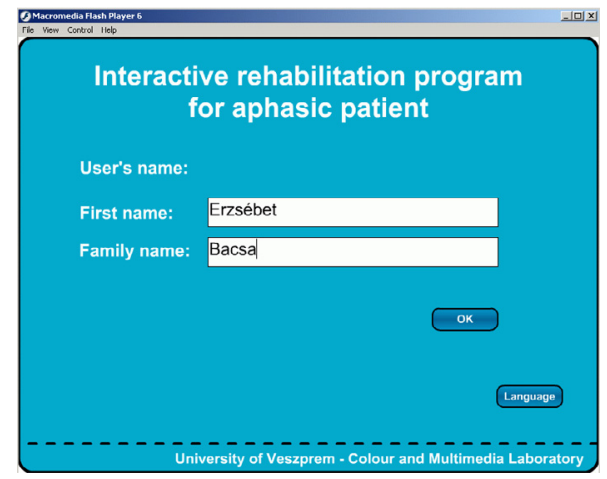

Figure 2: Submenu - User's name 
You can get into the next level only after filling in the User's name field. Then you can choose a room. (Fig. 3) The main task of the software is to teach the everyday words of the house or of the environment around to the house. In every submenu there are 4 skill levels (Fig. 4).

The first level acquaints the user with the objects of the room (Fig. 5). If the user points with the mouse to an object, the name of the object appears on the screen and it can be read. This first skill level trains the user's memory power.

The second level shows an uncoloured picture. The program asks the user to show the named object (Fig. 6). If the user manages to find the object requested it becomes coloured. In this way the user can make the whole picture colourful. If the user mixes the requested object with another one, the program informs him or her via a pop-up message, and then the task continues.

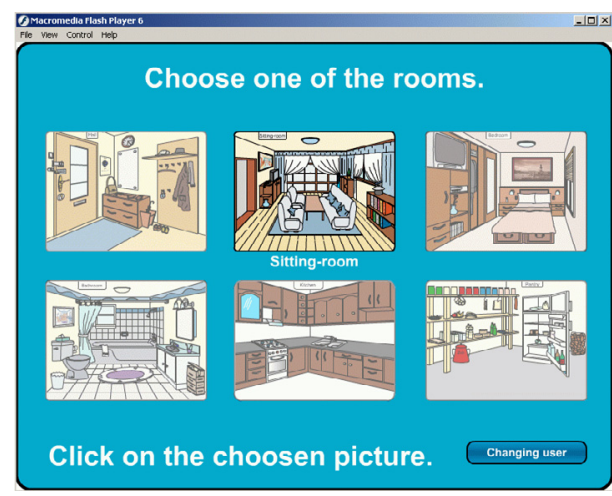

Figure 3: Submenu - rooms

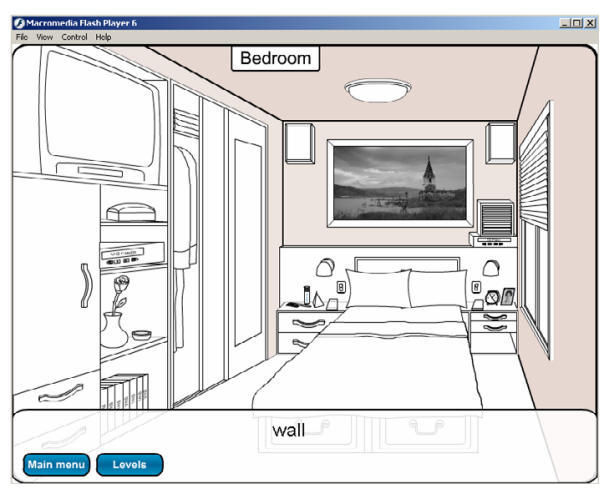

Figure 5: $1^{\text {st }}$ skill level

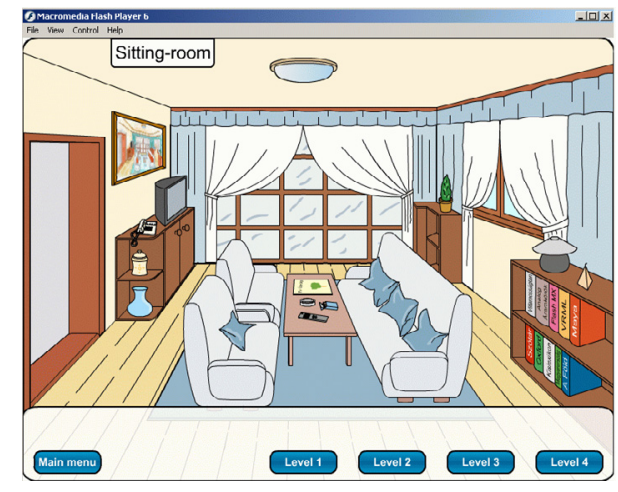

Figure 4: Menu of the room

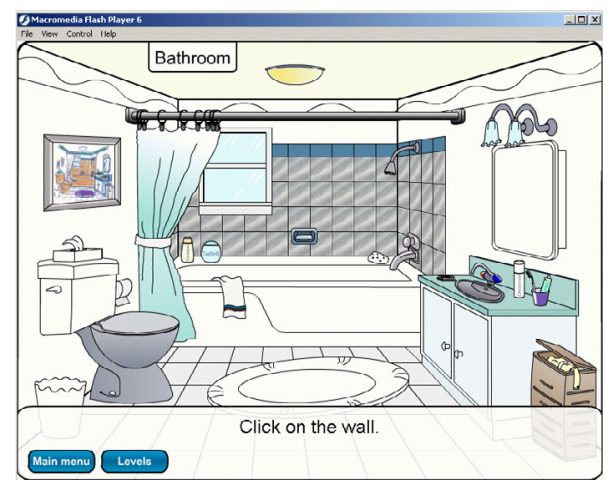

Figure 6: $2^{\text {nd }}$ skill level

A similar ability of the user is measured on the third level. The room used in the earlier task is in the background, but it is blurred. (Fig. 7) The program shows three figures randomly and the user has to choose one by answering a question. This is essential to test if the patient is now able to identify the item used for the asked function. The real knowledge is examined at this level.

If the user could not answer, the program sends an error picture. This third level asks questions until the user or the teacher chooses another skill level.

The fourth level asks more difficult questions than the third level. The questions deal with the handling of the objects (Fig. 8). If the user can find the object, the program asks its name and the user has to write it into an input row on the screen. After the correct answer the program asks a new question. 


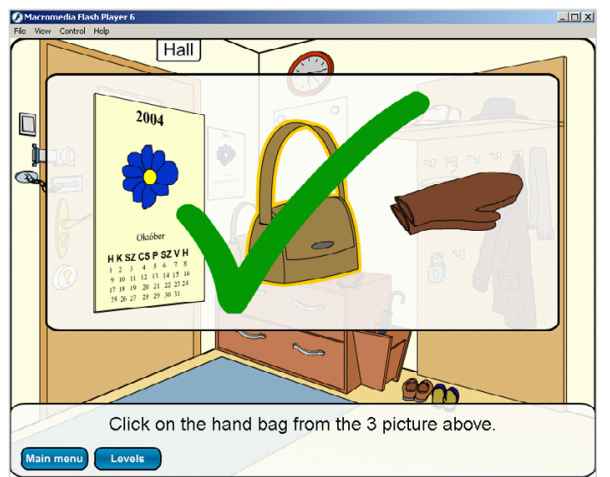

Fig. 7: $3^{\text {rd }}$ skill level

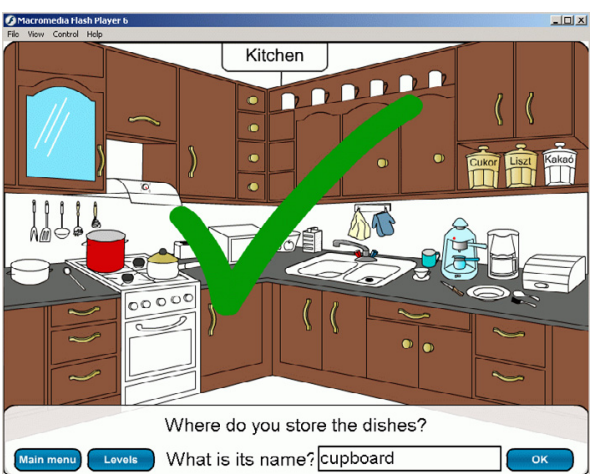

Fig. 8: $4^{\text {th }}$ skill level

The starting level and the tasks are chosen by the therapist, and it is the most effective when the practising is assisted by a therapist. According to the teachers and therapists suggestions, the program makes good use of simple animations, short videos as tools of motivation to reassure the users in their correct answers.

\section{The Virtual Home}

An average family house and its equipment are the most suitable for the mental treatment of aphasia stroke patients (Hajnal, 2005). The ideal situation would be to develop for every patient their own house. The patients would have their skills improved in this virtual environment. They could identify the objects in their familiar environment and would develop proper orientation in the environment. But it is an impossible task to develop a Virtual Home for every patient. The development of a Virtual Home is a difficult job and needs a lot of time; therefore, we paid much account of choosing the model of the house. We chose an average blueprint of built houses in Hungary.

To select a large enough floor space was the first important viewpoint, because we need enough moving possibility in the house. Modelling the kitchen was our first task. There are the most important household equipments and objects for the everyday life in the kitchen, and there are many potential accidents. The user can find the ordinary kitchen equipment, for example the microwave oven, the fridge, the gas-cooker and so on in our model kitchen. There are some possibilities to extend the equipment, objects, and of course the house.

\section{The Modelling}

At the designing phase we had to take into account that we were developing a virtual environment for aphasia patients. This produced some special tasks, for example we did not model a very modern, new and futuristic house, because an unreal virtual environment will not be acceptable by our patients.

One of the most important expectations of the virtual house is to contain a lot of objects. In this case the patient's task at this rehabilitation phase is to name an ever increasing number of objects. As the variety of objects increases, so do the tasks. The modelled objects are typical ones; all the patients met these objects earlier in their life (Fig. 9 and Fig. 10). The everyday objects are for example: cup, plate and knife. We modelled the objects in such a form that their shapes are very simple and ordinary. 

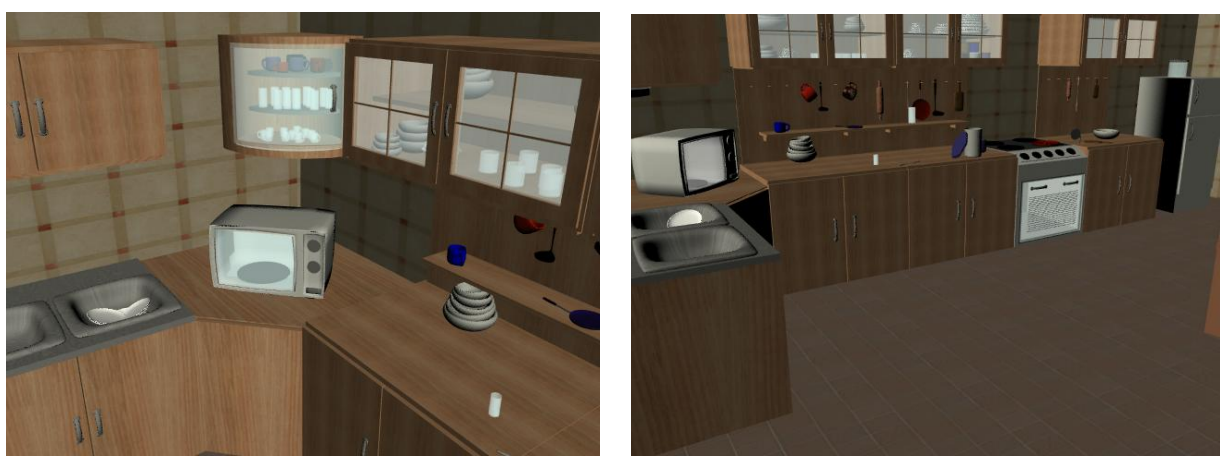

Fig. 9: The kitchen
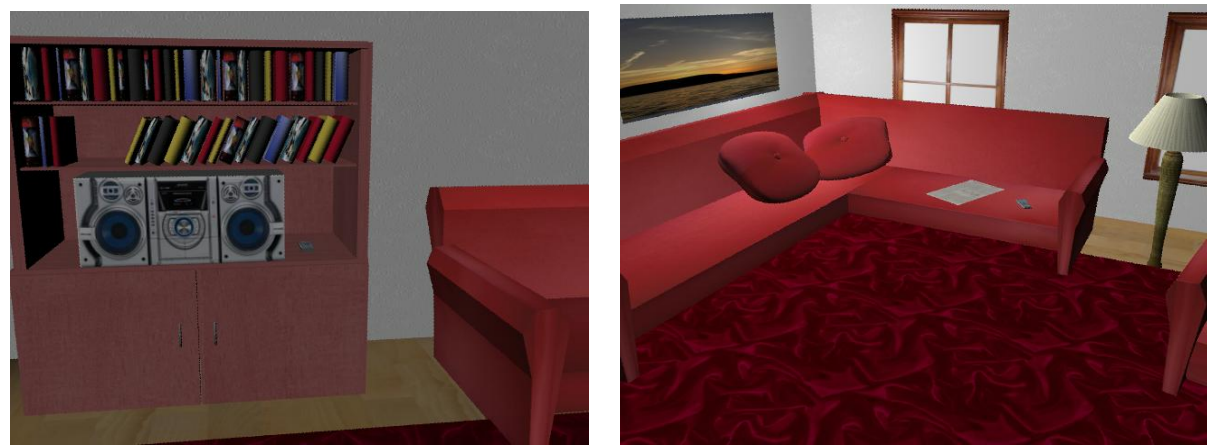

Fig. 10: The living room

\section{The Tasks in the Virtual Home}

The tasks in the Virtual Home:

- To name the object: The patient has to name the objects when the therapists points on them.

- To find one place in the building: The patient has to learn to orient himself in the house. Thus for example he or she has to find the way to the kitchen from a pre-defined place set by the doctor.

- To find the objects in the building by their name: This is already a very complex task; for example the patient gets the task to find the cup. Then knowledge is needed on his or her exact location, on the direction in which the search should be started, and obviously on the location where the cup might be found. If the patient reaches the correct location he or she has to identify the cup.

- Checking the route: The therapist investigates how easily the patients get from one place to the other, how well they orient themselves.

- To practise everyday tasks: The patient gets the opportunity to perform everyday tasks, such as to set a table. The patient can also determine the order of different tasks. We hope that the virtual world can be used in the cases of patients with mild and not too heavy brain damage. 


\section{Test Results of the Word-instructor Multimedia Software}

Our primary field of testing was the Kozmutza Flora Special Primary School and Talent Developing College, since the original call came from there. Secondly the efficiency examinations took place in the National Centre of Brain Vein Diseases in Budapest. Both processes ended with promising results.

In the first phase, not only the students but also their teachers took part in the testing which instantly made clear that the program is easy to use for both trainee and pupil. In the teachers' opinion it is a tool capable for more general use: not only for aphasic children, but also for others with similarly severe learning difficulties.

The psychologists' initial feedback after the second period of testing gave direct suggestions for further improvement. Firstly it was suggested that the software should be amplified with a database while motivating animations and tasks should be made optional since adult users are not really interested in them. In addition, a distinction should be made between the addressing of youngsters and adults, since the former group is usually addressed by their first name, while the latter by their last name according to language traditions.

The testing in naming objects tasks has been conducted with the participation of five subjects up to now. The first three levels of exercises were passed easily by all of them. Obviously the first level did not cause any problem; it rather helped the familiarisation of the software itself.

The second task was the "painting" task, whose scoring is displayed in Table 1. The first column shows the number of the objects that were found by the patients immediately. Column number 2 shows the number of the objects that were found by the patients at second trial, and so on. $91 \%$ of the objects were found at the first session. It was an easy task for every patient (Table 1).

\begin{tabular}{|l|r|r|r|r|r|r|r|r|r|r|}
\hline \multicolumn{1}{|c|}{ Table 1: Number of correct answers at the $\mathbf{2}^{\text {nd }}$ level } \\
\hline Number of attempts & $\mathbf{1}$ & $\mathbf{2}$ & $\mathbf{3}$ & $\mathbf{4}$ & $\mathbf{5}$ & $\mathbf{6}$ & $\mathbf{7}$ & $\mathbf{8}$ & $\boldsymbol{\Sigma}$ \\
\hline $1^{\text {st }}$ person & 29 & 4 & & 1 & & & & & \\
\hline $2^{\text {nd }}$ person & 30 & 2 & & & & & & & \\
\hline $3^{\text {rd }}$ person & 8 & 1 & & & 1 & & & & \\
\hline $4^{\text {th }}$ person & 29 & & & & & & & & \\
\hline $5^{\text {th }}$ person & 28 & 2 & & 1 & 1 & & & & \\
\hline$\Sigma$ & 124 & 9 & & 2 & 2 & & & & 137 \\
\hline$\%$ & 91 & 7 & & 1.5 & 1.5 & & & & \\
\hline
\end{tabular}

The fact that all people save one were unable to find all the objects for the first trial might be strange. But the answer lies in the size of the objects: the missed ones were of a very small size or placed somehow a bit hidden in the rooms. For example in the living room: frame, candle, flower, cigarette, or in the bathroom: toothbrush, soap, soap-dish, body lotion. Taking this into account, the testers' achievements become less fruitless, even the mistakes could be discarded.

In the $3^{\text {rd }}$ level the users were shown 3 objects, and had to mark the named one with the mouse cursor. Column 1 of Table 2 shows the number of objects that were found by the patients immediately. Column 2 shows the number of objects that were found by the patients participating in the second trial, and so on. $94 \%$ of the objects were found at the first attempt (Table 2). 
Table 2: Number of correct answers at the $3^{\text {rd }}$ level

\begin{tabular}{|l|r|r|r|r|r|r|r|r|r|}
\hline Number of attempts & $\mathbf{1}$ & $\mathbf{2}$ & $\mathbf{3}$ & $\mathbf{4}$ & $\mathbf{5}$ & $\mathbf{6}$ & $\mathbf{7}$ & $\mathbf{8}$ & $\mathbf{\Sigma}$ \\
\hline $1^{\text {st }}$ person & 14 & 1 & & & & & & & \\
\hline $2^{\text {nd }}$ person & 25 & & & & & & & & \\
\hline $3^{\text {rd }}$ person & 12 & 1 & & & & & & & \\
\hline $4^{\text {th }}$ person & 28 & & & & & & & & \\
\hline $5^{\text {th }}$ person & 28 & 2 & & 1 & 1 & & & & \\
\hline$\Sigma$ & 107 & 4 & & 1 & 1 & & & & 113 \\
\hline$\%$ & 94 & 4 & & 1 & 1 & & & & \\
\hline
\end{tabular}

The only problems arose from long or compound words, nearly all of the testers showed difficulty in locating them. For example: coffee table (in Hungarian it is even longer: dohányzóasztal) or videotape (in Hungarian: videókazetta).

The $4^{\text {th }}$ level task was the hardest of all, since the user is not able to select from possibilities, but has to type in the name of the requested object. We can see in Table 3, only $44 \%$ of the tasks were solved immediately, while the greater part of the questions were answered correctly only at a second, third or a later attempt.

\begin{tabular}{|l|r|r|r|r|r|r|r|r|r|r|}
\hline \multicolumn{1}{|c|}{ Table 3: Number of the errors at the $\mathbf{t}^{\text {th }}$ level } \\
\hline Number of attempts & $\mathbf{1}$ & $\mathbf{2}$ & $\mathbf{3}$ & $\mathbf{4}$ & $\mathbf{5}$ & $\mathbf{6}$ & $\mathbf{7}$ & $\mathbf{8}$ & $\mathbf{\Sigma}$ \\
\hline $1^{\text {st }}$ person & 1 & & & & 1 & 1 & & 1 & \\
\hline $2^{\text {nd }}$ person & 6 & 2 & 1 & & 1 & & & & \\
\hline $3^{\text {rd }}$ person & & 1 & 1 & 2 & & & & & \\
\hline $4^{\text {th }}$ person & 10 & 2 & 1 & 1 & & 1 & 1 & & \\
\hline $5^{\text {th }}$ person & & 1 & 2 & 1 & 1 & & & & \\
\hline$\Sigma$ & 17 & 6 & 5 & 4 & 3 & 2 & 1 & 1 & 39 \\
\hline$\%$ & 44 & 15 & 13 & 10 & 8 & 5 & 2.5 & 2.5 & \\
\hline
\end{tabular}

Here the problem of the long or compound words was accompanied by that of spelling, the difficulty of finding the necessary characters, mainly the accented letters. For example: gas-cooker = gáztüzhely, night-light = éjjelilámpa, oven - gloves = edényfogó kesztyü.

This problem must obviously be given special tasks in the future, to help patients overcome it, so new type of exercises will be included in the program. For example a possible jump back to the $1^{\text {st }}$ level from the $4^{\text {th }}$ one, to allow the user some sort of cribbing such as the use of a cheat-sheet. In addition, the instant use of this knowledge back in the $4^{\text {th }}$ level promotes its relocation into the long-term memory from the short-term one. Another seemingly obvious addition has been suggested, namely the integration of a very wide dictionary of synonyms into the software. It would make possible for the presented knowledge to reflect the world more naturally, and give better help in communication. These are our future plans. 


\section{Summary}

In the tumult of the achievements of today's computer technology fortunately remedial treatments have made good use of their tools. The new ways of representation of information and of the knowledge of the world in interactive programs offer great opportunities for the special needs user and those concerned with their state in society.

Although multimedia and virtual reality are primarily connected to games and entertainment in the mind of most people of the world, they are equally useful tools in medical employment. They can represent and imitate reality on such a high level that no other tool can offer. Software such as we've described reduce the perils of an on-field practice, while providing an easy and comfortable way of learning indirectly. Showing an object of the world accompanied by its name is the most obvious way of acquiring a foreign language. The same idea is the basis for our multimedia program and virtual environment for aphasic patients, although they do not learn a second language, but regain their knowledge of their own mother tongue.

Our program provides an exploration of an ordinary house with detailed features for the user. Therefore the vocabulary of our every-day environment is put into focus as well as the spelling. In addition, the elements in the rooms are shown in their familiar environment not in isolation, which has a further beneficial effect on the memorisation of their names, since this way patients gain a mental structure of related objects. For a smooth development the offered exercises are graded: the first level is still observation of the rooms while the last one is a typing task which is particularly difficult for patients of aphasia.

Although the "Word-instructor" is a bit limited in immersion due to the fact that the view-point of each room is fixed, but the patients can still feel "being there" through the many ways of interaction. Just think back: the objects of the rooms gain their colour through the users' deeds. On the other hand due to the selection and typing way of practising this software has a fairly close connection to ordinary practice books, which are a familiar way of learning.

The Virtual Home goes a huge step further: every former limitation on movement is passed. The house is beautifully realistic and every little corner is a subject of some exploration. The user can freely walk in the rooms, rotate head to change the line of sight and can easily feel as if they are a part of the environment. These features allow more complex and realistic tasks for practise, for example the location exercise can come with the need to get to another corner of the room to find an object unseen from the former position, or even a fairly long walk to another room. It has new methods for the therapists monitoring their patients' use of the program as well: they can investigate the patients' level of orientation and motion in the house. But the ultimate feature of the program is that it makes possible for the user to perform every-day tasks.

The majority opinion of the users - both therapists-teachers and patients -was that the programs were very useful and approached the problem from a well-chosen perspective. For a wide range of users, they were even more welcome than ordinary therapy, which is likely caused by the fact that the patients had been already familiar with the computer while possibly having some antipathy against "mystic" therapies. The statistical results of the users' achievements in the "Wordinstructor" were also promising, the arisen suggestions were rather aims at expanding the programs than change their elements. A new direction is opened in aphasia rehabilitation, now we must proceed further on it.

\section{Acknowledgements:}

The authors would like to acknowledge the help of university students Ms. Erzsébet Bacsa and Mr. Zoltán Hajnal, who carried out programming and Maya modelling. 


\section{References}

Bacsa, E., (2004). Developing interactive multimedia rehabilitation software for aphasic patients. MSC Thesis Work, University of Veszprém.

Bongár, Sz.., Várady, P., \& Fördős, G., (2003). Neuro-linguistic software supporting the rehabilitation of aphasic patients (Afáziás betegek terápiáját segítő neurolingvisztikai szoftver). Medical and Hospital Engineering (Orvos- és kórháztechnika), Vol XLI. Num 5, 2003, pp: 135-137. Retrieved Marz 06, 2006 from www.orki.hu/orkotech/2003/Orki\%202003-05.pdf

Bowman, D.A., Kruijff, E., LaViola Jr., J.J., \& Poupyrev, I. (2004). 3D user interfaces (p. 7). AddisonWesley.

Broeren, J., Georgsson, M., Rydmark, M., \& Stibrant Sunnerhagen, K. (2002). Virtual reality in stroke rehabilitation with the assistance of haptics and telemedicine. In Sharkey, Sik Lányi \& Standen (Eds.), Proceedings of the $4^{\text {th }}$ Intl Conf. on Disability, Virtual Reality and Assoc. Technologies (pp. 71-76), Veszprém, Hungary, 18-20 Sept.

Connor, B.B., Wing, A.M., Humphreys, G.W., Bracewell, R.M., \& Harvey, D.A. (2002). Errorless learning using haptic guidance: Research in cognitive rehabilitation following stroke. In Sharkey, Sik Lányi \& Standen (Eds.), Proceedings of the $4^{\text {th }}$ Intl Conf. on Disability, Virtual Reality and Assoc. Technologies (pp. 77-83), Veszprém, Hungary, 18-20 Sept.

Davies, R.C., Löfgren, E., Wallergård, M., Lindén, A., Boschian, K., Minör, U., Sonesson, B., \& Johansson, G. (2002). Three applications of virtual reality for brain injury rehabilitation of daily tasks. In Sharkey, Sik Lányi \& Standen (Eds.), Proceedings of the $4^{\text {th }}$ Intl Conf. on Disability, Virtual Reality and Assoc. Technologies (pp. 93-100), Veszprém, Hungary, 18-20 Sept.

Edmans, J.A., Gladman, J., Walker, M., Sunderland, A., Porter, A., \& Stanton Fraser D. (2004). Mixed reality environments in stroke rehabilitation: development as rehabilitation tools, The $5^{\text {th }}$ International Conference on Disability, Virtual Reality and Associated Technologies (pp. 3-10), Oxford, UK, 20-22 Sept.

Hajnal, Z. (2005). Designing and developing a Virtual Home for aphasia patients. MSC Thesis Work, University of Veszprém.

Kizony, R., Katz, N., Weingarden, H., \& Weiss, P.L. (2002). Immersion without encumbrance: adapting a virtual reality system for the rehabilitation of individuals with stroke and spinal cord injury. In Sharkey, Sik Lányi \& Standen (Eds.), Proceedings of the $4^{\text {th }}$ Intl Conf. on Disability, Virtual Reality and Assoc. Technologies (pp. 55-62), Veszprém, Hungary, 18-20 Sept.

Kizony, R., Katz, N., \& Weiss, P.L. (2004). Virtual reality based intervention in rehabilitation: Relationship between motor and cognitive abilities and performance within virtual environments for patients with stroke. In Sharkey, McRindle \&Brown (Eds), Proceedings of the $5^{\text {th }}$ Intl Conf. on Disability, Virtual Reality and Assoc. Technologies (pp. 19-26), Oxford, UK, 20-22 Sept.

Lam, Y.S., Tam, S.F., Man, D.W.K., \& Weis, P.L. (2004). Evaluation of a computer assisted 2D interactive virtual reality system in training street survival skills of people with stroke. The $5^{\text {th }}$ International Conference on Disability, Virtual Reality and Associated Technologies (pp. 27-32), Oxford, UK, 20-22 Sept.

Lo Priore, C., Castelnuovo, G., \& Liccione, D. (2002). Virtual environments in cognitive rehabilitation of executive functions. In Sharkey, Sik Lányi \& Standen (Eds.), Proceedings of the $4^{\text {th }}$ Intl Conf. on Disability, Virtual Reality and Assoc. Technologies (pp. 165-172), Veszprém, Hungary, 18-20 Sept.

MacDonald, L.W. (1996). Colour image reproduction: The evolution from print to multimedia. SPIE/Europto Conference on Imaging Sciences and Display Technologies, Berlin, Proc. SPIE, Vol. 2949, pp. 246-251.

Maureen W. (2005). Explaining aphasia [PowerPoint presentation] Captain, Support Services, Brookfield, CT Police Department. Retrieved Marz 06, 2006, from http://www.aphasia.org/infopacketonline.php 
Maxhall, M., Backman, A., Holmlund, K., Hedman, L., Sondell, B., \& Bucht. G. (2004). Participants responses to a stoke training simulator. In Sharkey, McRindle \&Brown (Eds), Proceedings of the $5^{\text {th }}$ Intl Conf. on Disability, Virtual Reality and Assoc. Technologies (pp. 225-230), Oxford, UK, 20-22 Sept.

Medve, A., Szakolczai, K., \& Kozmann Gy. (2004). IT models for e-health application processes. In International Conference Overcoming the Barriers to e-he@lth Growth in Enlarged Europe 2004 (pp. 927), Krakow, ProAccess.

Morris, R.G., Kotitsa, M., Bramham, J., Brooks, B., \& Rose, F.D. (2002). Virtual reality investigation of strategy formation, rule breaking and prospective memory in patients with focal prefrontal neurosurgical lesions. In Sharkey, Sik Lányi \& Standen (Eds.), Proceedings of the $4^{\text {th }}$ Intl Conf. on Disability, Virtual Reality and Assoc. Technologies (pp. 101-108), Veszprém, Hungary, 18-20 Sept.

Morris, R.G., Parslow, D.M., Fleminger, S., Brooks, B., Giametro, V., \& Rose, F.D. (2002). Functional magnetic resonance imaging investigation of allocentric spatial memory using virtual reality in patients with anoxic hippocampal damage. In Sharkey, Sik Lányi \& Standen (Eds.), Proceedings of the $4^{\text {th }}$ Intl Conf. on Disability, Virtual Reality and Assoc. Technologies (pp. 87-92), Veszprém, Hungary, 18-20 Sept.

Óváry, C. \& Nagy, Z. (1999). Prospective study on stroke epidemiology, Hungarian stroke database. $1 s t$ Congress of the Central and Eastern European Stroke Society, Budapest.

Pridmore, T., Hilton, D., Green, J., Eastgate, R., \& Cobb, S. (2004). Mixed reality environments in stroke rehabilitation: Interfaces across the real/virtual divide. The $5^{\text {th }}$ International Conference on Disability, Virtual Reality and Associated Technologies (pp. 11-18), Oxford, UK, 20-22 Sept.

Sik Lányi C., Bacsa E., Mátrai R., Kosztyán Zs. (2004) The use of interactive rehabilitation software for treating patients with aphasia. $5^{\text {th }}$ International Conference on Disability, Virtual Reality and Associated Technologies ICDVRAT 2004 (pp. 233-238), 20-22 September, Oxford, UK.

Sik Lányi, C., Bacsa, E., Mátrai, R., Kosztyán, Zs., \& Pataky, I. (2004). The Design Question of Development of Multimedia Educational Software for Aphasia Patients. In K. Miesenberger et al. (Eds.), Computers Helping People with Special Needs (pp. 6-13). Springer Press.

Sik Lányi, C., \& Hajnal, Z. (2005). Design and developing a Virtual Home for aphasia patients. Assistive Technology from Virtuality to Reality, 8th European Conference for the Advancement of Assistive Technology in Europe (pp. 158-162), Lille - France - September 6-9.

Sik Lányi C. (2006). Virtual Reality in Healthcare. In A. Ichalkaranje et al. (Eds.), Intelligent Paradigms in Assistive and Preventive Healthcare (pp. 92-121). Springer-Verlag.

Spaniol, M., Springer, L., Klamma, R., \& Jarke, M. (2004). SOCRATES: Barrier free communities of aphasics on the Internet. K. Miesenberger et al. (Eds.), Computers helping people with special needs (pp. 1024-1031). Springer Press.

Stanney, K.M. (2002). Handbokk of virtual environments (pp. 301-302). LEA, London.

Stark J. (1998). Everyday life activities photo series manual set 3, (English, French (Pons, C.), Italian (Magris, M.), Spanish (Martínez, L.), Wien: Druckerei Jentzsch.

Stark J. (2003). Everyday life activities object photo series manual set 1, (English, Deutsch (Stark, J.), French (Pons, C.), Italian (Pomes, R., Fabris, M., Tonelli. L.), Spanish (Martínez, L.), Wien: Druckerei Jentzsch.

Stark, J. (2005). Analyzing the therapy process: The implicit role of learning and memory, Aphasiology, 19 (10/11), 1074-1089.

Takácsné Csór, M. (1986). Speak without fear! Exercise book for the therapy of aphasia, Beszélj bátran Feladatgyüjtemény az afázia terápiához, Tankönyvkiadó Budapest

Wallergård, M., Cepciansky, M., Lindén, A., Davies, R.C., Boschian, K., Minör. U., Sonesson, B., \& Johansson., G. (2002). Developing virtual vending and automatic service machines for brain injury rehabilitation. In Sharkey, Sik Lányi \& Standen (Eds.), Proceedings of the $4^{\text {th }}$ Intl Conf. on Disability, Virtual Reality and Assoc. Technologies (pp. 109-114), Veszprém, Hungary, 18-20 Sept. 


\section{Biographies}

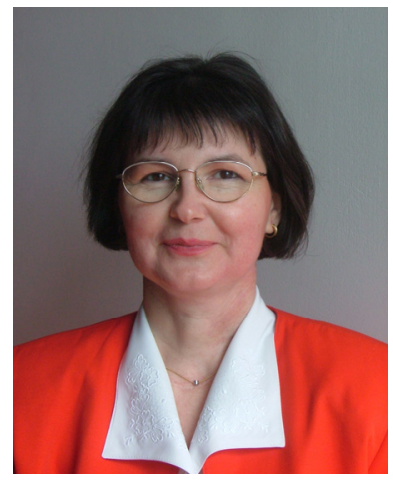

Cecília Sik Lányi is associate professor at the University of Veszprém, Virtual Environment and Imaging Technologies Laboratory. She studied Mathematics and Computer Science (M.S.) - József Attila University, Szeged (1984), and teacher of mathematics (Berzsenyi Dániel Teacher Training College in 1988). She obtained the degree of Dr. Univ. at the University of Veszprém, Veszprém, Hungary in Physicalchemistry (1993), and of PhD at the University of Veszprém, Hungary in Computer Science (2000). She reads and leads laboratory studies on Multimedia, Virtual Reality, Programming the WEB, User Interface Design, Computer Graphics and Design. Her research area is in Multimedia, Virtual Reality, Human Computer Interaction, Design for All in education and rehabilitation.

She was the sub-project leader of "Computer system to support cognitive therapy" of Hungarian project: "Information Technology for Cost efficient Health Conservation"

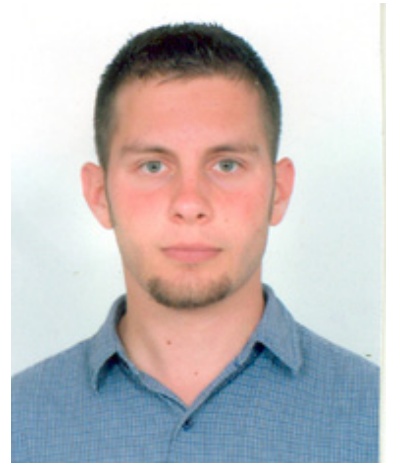

Zoltán Geiszt is a student of Information Science and Technology $\mathrm{PhD}$ School at the University of Veszprém since September 2005. He wrote his diploma dissertation on industrial automation, more precisely on position-controlling of several induction motors via CANopen communication and got his MSc degree in June 2005. Now he is dealing with Multimedia and Virtual Reality research, investigating presence-specific questions in various virtual environments with different emotive avatars.

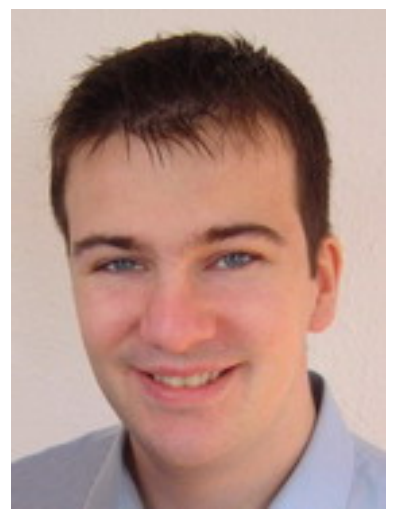

Viktor Magyar is a graduating student at the University of Veszprém. His research area is multimedia software development for users with different types of special needs. Some of his programs are already in use. His MSc dissertation deals with multimedia software development for hearing impaired children and its use in their rehabilitation. After graduating he would like to apply for admission to Information Science and Technology PhD School. 